\title{
Frequency of ocular metastases in patients dying of cancer in eye bank populations
}

Department of Ophthalmology and Visual Sciences, University of Wisconsin Medical School, Madison, WI, USA

B Eliassi-Rad

D M Albert

Wilmer Institute, Johns Hopkins University, Baltimore, MD, USA

W R Green

Correspondence to: Daniel M Albert, $\mathrm{MD}$, Department of

Ophthalmology and Visual Sciences, F4/334 600 Highland Avenue, Madison, WI 53792-3220, USA.

Accepted for publication 9 November 1995

\begin{abstract}
Aims-To examine the frequency of intraocular metastases in patients who had died of cancer, in an eye bank and necropsy population sample.

Methods-The first group included 302 cancer cases received from the Wisconsin Eye Bank between 1988 and 1993. In the second group, ocular pathology records at the Wilmer Institute from 1976 to 1980 were analysed for ocular metastases in necropsy subjects dying of cancer. Nonocular cancer was the cause of death in 741 cases; among these, 510 were attributed to carcinomas.
\end{abstract}

Results-In the Wisconsin Eye Bank group, three cases $(1 \%)$ had gross metastases. Out of 255 carcinoma cases, one $(0.4 \%)$ had gross metastases. In the Wilmer Institute group, gross metastases were observed in $35(4 \cdot 7 \%)$ cases. Of the 510 patients dying of carcinomas, six $(1 \cdot 2 \%)$ had macroscopic metastases. Ocular metastases were detected histopathologically in 93 of $741(12 \cdot 6 \%)$ of cases.

Conclusion-Even though it is difficult to assess the true frequency of ocular metastases in patients dying of cancer, the answer to this question was attempted by determining the frequency of ocular metastasis in patients who died of cancer and who donated their eyes to the Wisconsin Eye Bank or had postmortem examination at the Johns Hopkins Hospital. Microscopic metastases were found in $12.6 \%$ of cases. The frequency of gross metastases has decreased over the past 12 years from $4 \cdot 7 \%$ to $1 \%$ ( $p$ value $=0.005$ ) owing to improved treatment of leukaemia; however, the frequency of macroscopic metastases due to carcinomas has not changed ( $p$ value $=0 \cdot 38$ ). (Br f Ophthalmol 1996; 80: 125-128)

Horner in $1864^{1}$ and Perl in $1872^{2}$ were the first to describe metastatic disease in the eye. Since that time, reports of ocular metastases have steadily accumulated. ${ }^{34}$ In a clinical study in 1944, Godtfredson ${ }^{5}$ reported that, of 8712 patients with metastatic cancers referred for radiation therapy, six $(0.07 \%)$ had ocular involvement. In 1967, Albert et al ${ }^{6}$ found, by ophthalmoscopic examination, intraocular metastases in five of $213(2 \cdot 3 \%)$ patients with known metastatic carcinoma.

The rate of ocular metastasis is even higher in postmortem studies since occult microscopic disease can be detected. In a postmortem study involving 230 patients, Bloch and Gartner ${ }^{7}$ found 23 cases $(10 \%)$ to have metastases to the globe. In a prospective histopathological study of eyes from 716 subjects who had malignant neoplasms at the time of death, Nelson et $a^{3}$ found ocular metastases in $52(7 \cdot 3 \%)$. They also observed that of 376 patients, dying of all types of carcinoma, $15(4.0 \%)$ had ocular metastases. Of 512 patients with uveal metastases in the files of the Wills Eye Hospital, Shields et $a l^{8}$ found that the iris was also involved in $40(7 \cdot 8 \%)$.

As patients with metastatic malignancies live longer, ocular metastases will be detected more frequently. ${ }^{4}$ Although the prognosis of patients with ocular metastases is poor, if such lesions are detected early enough, they can be treated effectively with radiation therapy to improve vision and help maintain the quality of the patient's life. ${ }^{9} 10$

Intraocular metastases are the most common malignancy of the eye. ${ }^{71112} \mathrm{We}$ examined two groups of postmortem eyes (one by the dissecting microscope and the other histopathologically) to obtain information regarding the frequency of intraocular metastases in patients who have died of cancer.

\section{Materials and methods}

The study consisted of two groups. The first group included eyes donated to the Wisconsin Eye Bank. A total of 11553 pairs of eyes were donated to the Wisconsin Eye Bank between 1988 and 1993. The eye bank accepts all eyes except those from donors who have rabies, hepatitis, encephalitis, HIV, septicaemia, and

Table 1 Frequency of gross ocular metastases in patients dying of cancer from Wisconsin Eye Bank

\begin{tabular}{lcl}
\hline Primary malignancy & $\begin{array}{l}\text { Number of } \\
\text { patients examined }\end{array}$ & $\begin{array}{l}\text { Number of } \\
\text { ocular metastases }\end{array}$ \\
\hline Leukaemia & 25 & 1 \\
Lymphoma & 10 & 0 \\
Multiple myeloma & 8 & 1 \\
Sarcoma & 4 & 0 \\
Bladder & 8 & 0 \\
Brain & 6 & 0 \\
Breast & 14 & 0 \\
Cervical & 1 & 0 \\
Colorectal & 23 & 0 \\
Cutaneous melanoma & 2 & 0 \\
Oesophagus & 2 & 0 \\
Gall bladder & 1 & 0 \\
Gastric & 3 & 0 \\
Head and neck & 3 & 0 \\
Hepatic & 5 & 0 \\
Lung & 81 & 0 \\
Ovary & 10 & 0 \\
Pancreas & 12 & 1 \\
Prostate & 28 & 0 \\
Renal & 3 & 0 \\
Squamous cell & 1 & 0 \\
Unknown primary & 4 & 0 \\
Unspecified cancer & 48 & 0 \\
Total & 302 & 3 \\
Total carcinoma & 255 & 1 \\
\hline
\end{tabular}




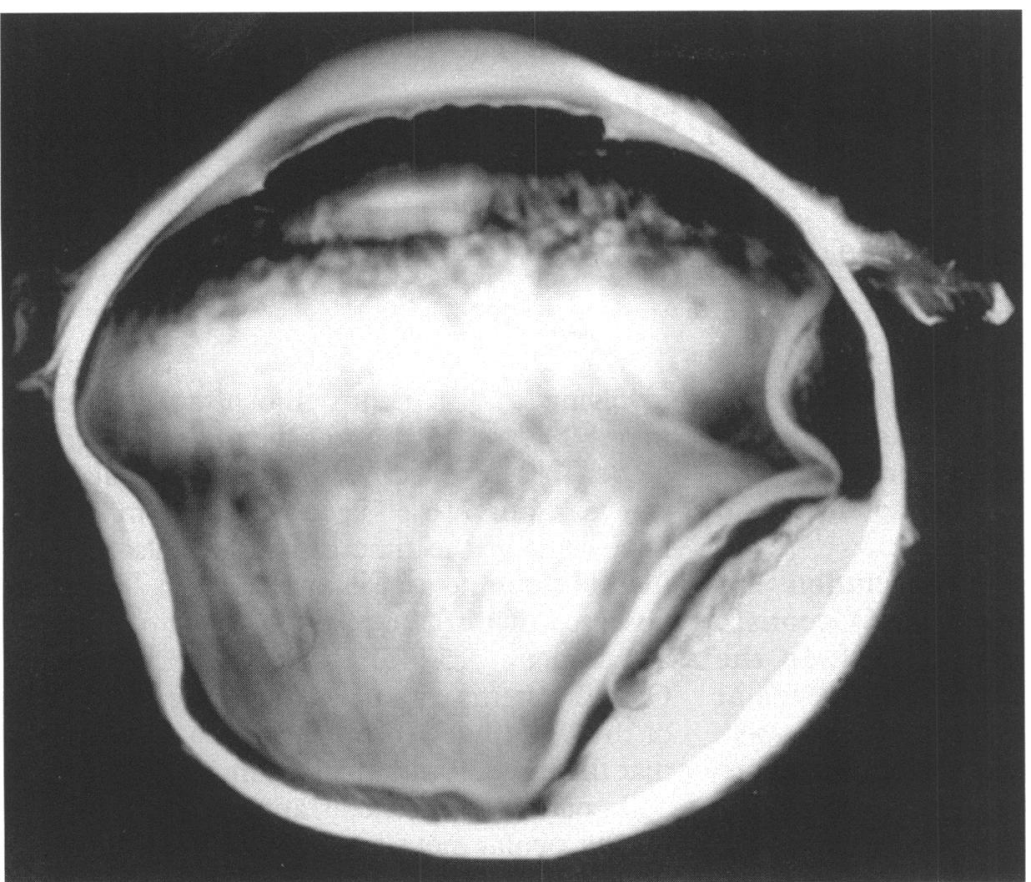

Figure 1 The left eye of a patient with gross metastasis to the choroid. The primary site was prostate $(\times 1 \cdot 25)$.

\section{Results}

The results from the Wisconsin Eye Bank group are summarised in Table 1 . Of 302 subjects three $(1.0 \%)$ had gross abnormalities and intraocular metastases were proved by histological sections. The causes of death were chronic leukaemia, multiple myeloma, or pancreatic carcinoma (Fig 1).

In the group from the Wilmer Institute, a total of 741 cases were found in which cancer was the cause of death. Of these, macroscopic metastases were observed in $35(4.7 \%)$ cases (Table 2). Gross metastasis was found in seven of $510(1.4 \%)$ patients dying of carcinoma; 15 of $115(13.0 \%)$ subjects with leukaemia, and four of $60(6 \cdot 7 \%)$ with lymphoma.

Microscopic metastasis was observed in 93 $(12.6 \%)$ of the 741 subjects. Ocular involvement was observed in 40 of $115(34.8 \%)$ patients dying with various types of leukaemia and in 14 of $60(23.3 \%)$ patients with lymphoma. The frequency of ocular involvement with various types of sarcoma as the primary tumour was four of $25(16 \%)$ (Table 3).

In 510 subjects dying of carcinoma, 25 $(5 \cdot 1 \%)$ had microscopic metastases. Nine of $147(6 \cdot 1 \%)$ and three of $36(8 \cdot 3 \%)$ subjects with lung and breast carcinoma, respectively, had ocular involvement (Figs 2 and 3). No ocular metastases were described in cases of colorectal cancer (Table 4). However, donated eyes of patients who die of other cancers may be used for corneal transplantation, if the patient is younger than 65 and there is no evidence of gross ocular metastasis. Of the total number of eyes received, 1476 were not used for transplant and were submitted to the eye pathology laboratory; 302 of these subjects had died of non-ocular cancers. Formalin fixed eyes were dissected in the horizontal meridian and examined under the dissecting microscope. When evidence of metastasis was found, the eye was processed for light microscopy by standard methods. ${ }^{3}$ Histological sections were stained with haematoxylin and eosin and examined by light microscopy.

In the second group, ocular pathology records at the Wilmer Eye Institute from 1976 to 1980 were analysed for cancer as the cause of death and for intraocular metastases. A total of 741 subjects died of cancer and their eyes were obtained at necropsy performed at the Johns Hopkins Hospital or from the Maryland Eye Bank. Eyes were examined by transillumination, macroscopically, and microscopically at the Wilmer Institute.

Table 2 Frequency of gross ocular metastases in patients dying of cancer from fohns Hopkins Hospital

\begin{tabular}{lll}
\hline Primary malignancy & $\begin{array}{l}\text { Number of } \\
\text { patients examined }\end{array}$ & $\begin{array}{l}\text { Number with ocular } \\
\text { metastases (\%) }\end{array}$ \\
\hline Leukaemia & 115 & $16(13 \cdot 0)$ \\
Lymphoma & 60 & $4(6 \cdot 7)$ \\
Multiple myeloma & 31 & $7(22 \cdot 6)$ \\
Sarcoma & 25 & $1(4 \cdot 0)$ \\
Carcinoma & 510 & $7(1 \cdot 4)$ \\
Lung & 147 & $4(2 \cdot 7)$ \\
Breast & 36 & 0 \\
Oropharynx & 21 & $1(4 \cdot 8)$ \\
Ovarian & 16 & $1(6 \cdot 3)$ \\
Pancreas & 28 & $1(3 \cdot 6)$ \\
Other & 262 & 0 \\
Total & 741 & $35(4 \cdot 7)$ \\
\hline
\end{tabular}

\section{Discussion}

In the present study, microscopic metastasis was found in 93 of $741(12.6 \%)$ of patients dying of all cancers. In a postmortem examination of 230 patients who died of systemic carcinoma, Block and Gartner ${ }^{7}$ reported 23 cases $(10 \%)$ with metastases to the globe. In another postmortem histopathological study from 1973 to 1982 , Nelson and coworkers ${ }^{3}$ performed ocular examinations on at least one eye from each body with a malignant neoplasm and undergoing necropsy at Duke University Medical Center. They found that 52 of 716 $(7 \cdot 3 \%)$ subjects had intraocular metastases. Additionally, Ferry and Font ${ }^{11}$ reported that out of 227 carcinoma cases metastatic to the eye or orbit in the Registry of Ophthalmic Pathology at the Armed Forces Institute of Pathology, 196 were metastatic to the globe (Table 5).

In the present study, ocular metastases were present in 25 of $510(5 \cdot 1 \%)$ patients dying of carcinoma. Additionally, ocular metastases were found in nine of $147(6 \cdot 1 \%)$ patients dying of lung cancer and three of $36(8.3 \%)$ patients dying of breast cancer. Bloch and

Table 3 Frequency of ocular metastasis in patients dying of cancer by histopathological study from the fohns Hopkins Hospital

\begin{tabular}{lll}
\hline Cancer & $\begin{array}{l}\text { Number of } \\
\text { patients examined }\end{array}$ & $\begin{array}{l}\text { Number with } \\
\text { ocular metastasis (\%) }\end{array}$ \\
\hline Leukaemia & 115 & $40(34 \cdot 8)$ \\
Lymphoma & 60 & $14(23 \cdot 3)$ \\
Multiple myeloma & 31 & $9(29 \cdot 0)$ \\
Sarcoma & 25 & $4(16 \cdot 0)$ \\
Carcinoma & 510 & $26(5 \cdot 1)$ \\
Total & 741 & $93(12 \cdot 6)$ \\
\hline
\end{tabular}




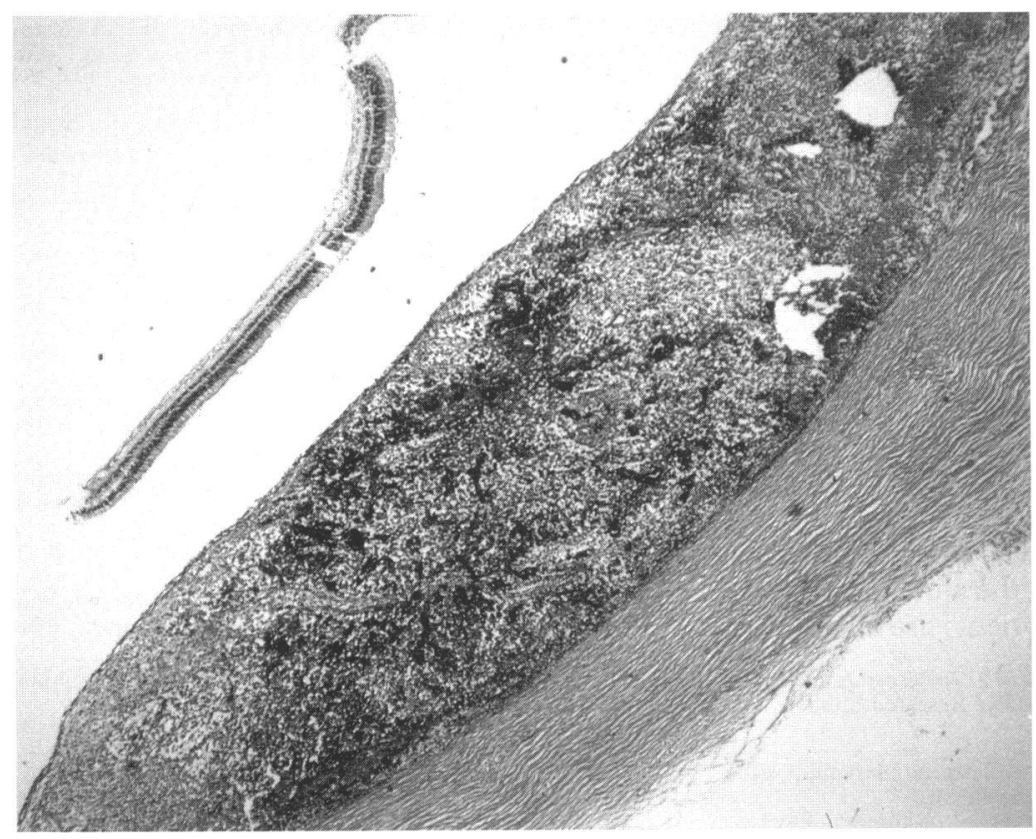

Figure 2 Histological section of the right eye showing a prominent focus of metastatic carcinoma involving the choroid (haematoxylin and eosin $\times 2 \cdot 25$ ).

Gartner ${ }^{7}$ found ocular metastases in 23 of 230 $(10 \%)$ patients dying of carcinomas. Ocular metastases were observed in three of $53(5 \cdot 7 \%)$ lung cancer patients and 19 of $52(36.5 \%)$ breast cancer patients. Nelson and coworkers ${ }^{3}$ detected ocular metastases in 15 of $376(4 \cdot 0 \%)$ patients dying of carcinomas. In their study, ocular metastases were present in six of 89 $(6 \cdot 7 \%)$ patients with lung carcinoma and 81 of $196(41 \cdot 3 \%)$ patients with breast carcinoma. In the study by Ferry and Font ${ }^{11} 62$ of 196 $(31 \cdot 6 \%)$ metastases to the eye were due to lung cancer and 81 of $196(41 \cdot 3 \%)$ were due to breast cancer.

In the Wilmer group, the frequency of gross ocular metastases in patients dying of carcinomas was $1.1 \%$ compared with $0.4 \%$ in the Wisconsin group. No statistical difference was detected between these two values $(p=0.38)$. In the Wilmer group, gross metastases were seen in nine of 147 lung

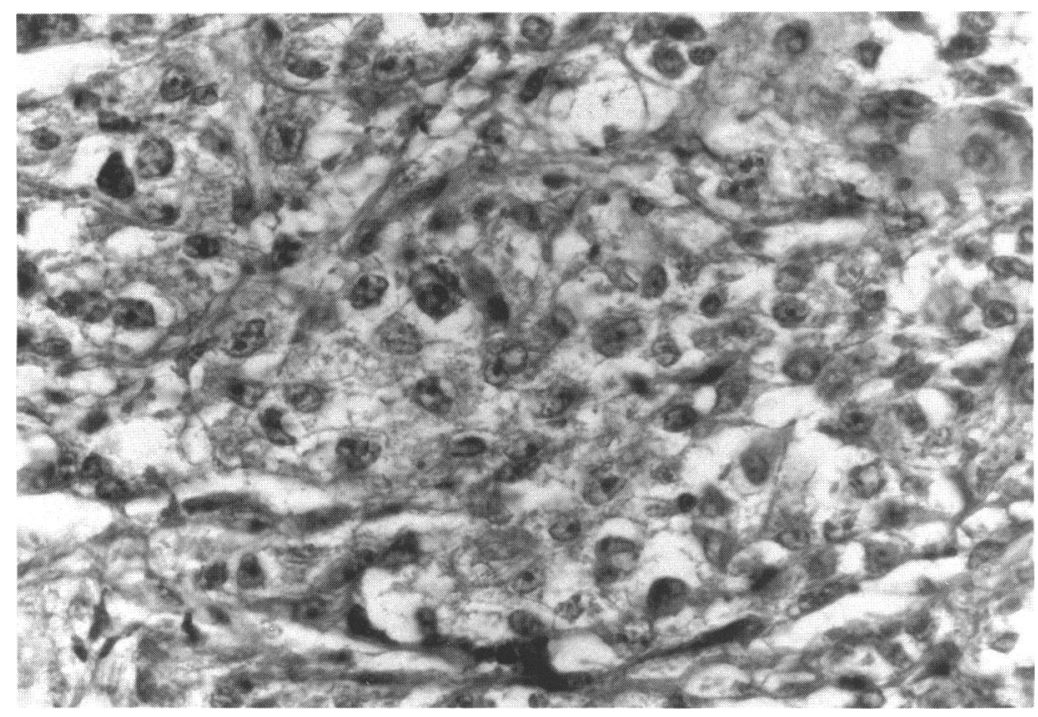

Figure 3 Histological section of the right eye showing a prominent focus of metastatic carcinoma involving the choroid (haematoxylin and eosin $\times 30$ ).
Table 4 Frequency of ocular metastases in patients dying of carcinomas by histopathological study from the Wilmer Institute

\begin{tabular}{lll}
\hline Primary tumour & $\begin{array}{l}\text { Number of } \\
\text { patients examined }\end{array}$ & $\begin{array}{l}\text { Number with } \\
\text { ocular metastases (\%) }\end{array}$ \\
\hline Lung & 147 & $9(6 \cdot 1)$ \\
Colorectal & 43 & 0 \\
Breast & 36 & $3(8 \cdot 3)$ \\
Prostate & 24 & $1(4 \cdot 2)$ \\
Urinary tract & 16 & 0 \\
Uterus & 20 & $1(5 \cdot 0)$ \\
Oral cavity, pharynx & 20 & $1(5 \cdot 0)$ \\
Skin & 14 & $2(14 \cdot 3)$ \\
Pancreas & 28 & $1(3 \cdot 6)$ \\
Ovary & 16 & $1(6 \cdot 3)$ \\
Neuroblastoma & 2 & $1(50)$ \\
Granulosa cell tumour & 1 & $1(100)$ \\
Liver, biliary passages & 13 & $1(7 \cdot 7)$ \\
Unknown primary & 3 & $1(33 \cdot 3)$ \\
Gastrointestinal & 5 & $1(20 \cdot 0)$ \\
Adenocarcinoma & 11 & $1(9 \cdot 1)$ \\
Other sites & 111 & 0 \\
Total carcinomas & 510 & $25(5 \cdot 1)$ \\
\end{tabular}

^Includes oesophageal, brain, hepatocellular, gastric, not specified, thyroid, adrenal, testicular.

cancer cases; and in the Wisconsin study, no macroscopic metastases were seen in 81 lung cancer cases. There was no statistical difference between these two values $(p=0 \cdot 31)$. In short, the frequency of ocular metastases in patients dying of carcinomas overall and lung cancer in particular have not changed in the past 12 years.

The overall frequency of gross intraocular metastasis in the present series has decreased from $4.7 \%$ to $1 \%$ over the past 12 years $(p=0.005)$. However, the frequency of metastases in eyes from patients with carcinomas has not changed with time $(p=0 \cdot 38)$. This decrease may be attributable to improvements in the treatment of lymphoproliferative malignancies.

The American Cancer Society provides estimates of the frequency of new cancer cases and cancer deaths in the United States annually. ${ }^{13}$ Extrapolating from these figures and from our data, a conservative estimate of the number of ocular metastases among fatal cases of cancer in the United States can be made (Table 6). In 1993, there were 526000 cancer deaths, 149000 from lung cancer and 43600 from breast carcinoma. Based on our data, 66000 cancer patients will have ocular metastases and among these, approximately 9100 with fatal lung carcinoma and nearly 4000 with fatal breast carcinoma.

Our results support previous data on frequency of ocular metastases. ${ }^{37}$ As cancer therapy improves, patients with metastatic cancer are surviving longer. ${ }^{4}$ Thus, one might expect to see more patients with ocular metastases. Additionally, $12-46 \%$ of patients with metastatic tumours present initially with ocular metastases and no other findings. ${ }^{11} 14$ Timely detection of ocular metastases in patients with

Table 5 Comparison of the frequency of ocular metastases

\begin{tabular}{|c|c|c|}
\hline Study & $\begin{array}{l}\text { Number of } \\
\text { cases }\end{array}$ & $\begin{array}{l}\text { Frequency of } \\
\text { ocular metastases (\%) }\end{array}$ \\
\hline $\begin{array}{l}\text { Bloch and Gartner } \\
\text { Nelson } e t a l^{3} \\
\text { Present study }\end{array}$ & $\begin{array}{l}230 \\
562 \\
741\end{array}$ & $\begin{array}{r}10 \cdot 0 \\
9 \cdot 3 \\
12 \cdot 6\end{array}$ \\
\hline
\end{tabular}


Table 6 An estimate of ocular metastases in the United States in 1993

\begin{tabular}{lccc}
\hline $\begin{array}{l}\text { Site of primary } \\
\text { malignancy }\end{array}$ & $\begin{array}{l}\text { Estimated cancer } \\
\text { deaths in } 1993^{14}\end{array}$ & $\begin{array}{l}\text { Percentage with } \\
\text { ocular metastases }\end{array}$ & $\begin{array}{l}\text { Estimated number of patients } \\
\text { with ocular metastases }\end{array}$ \\
\hline Lung & 149000 & $6 \cdot 1$ & 9089 \\
Breast & 46300 & $8 \cdot 3$ & 3843 \\
Prostate & 35000 & $4 \cdot 2$ & 1470 \\
Oral & 7700 & $4 \cdot 8$ & 370 \\
Skin & 6800 & $14 \cdot 3$ & 972 \\
Pancreas & 25000 & $3 \cdot 6$ & 900 \\
Ovary & 13300 & $6 \cdot 3$ & 838 \\
Cervical & 4400 & $8 \cdot 3$ & 365 \\
Multiple myeloma & 9400 & $29 \cdot 0$ & 6361 \\
Leukaemia & 18600 & $34 \cdot 2$ & 4884 \\
Lymphoma & 22000 & $22 \cdot 2$ & 66272 \\
Total & 526000 & $12 \cdot 6$ & \\
\hline
\end{tabular}

cancer is important because radiation therapy may improve vision and the quality of life in the remaining time the patients are alive.

Supported in part by NIH NEI EY01917, Research to Prevent Blindness and the Wisconsin Lions Eye Research Fund.

1 Horner F. Carcinoma der dura mater exophthalmus. Klin Monatsbl Augenheilkd 1864; 2: 186-90.

2 Perl M. Contributions to pathology of tumors. Virchows Arch $(A) 1872 ; 56: 445-8$.
3 Nelson CC, Kertzberg BS, Klintworth GK. A histopathologic study of 716 unselected eyes in patients with cancer at the time of death. Am $\mathcal{f}$ Ophthalmol 1983; 95: 788-93.

4 Volpe NJ, Albert DM. Metastases to the uvea. In: Albert DM, Jakobiec FA, eds. Principles and practice of ophthalmology. Philadelphia: WB Saunders, 1994: 3260-70.

5 Godtfredson E. On the frequency of secondary carcinoma in the choroid. Arch Ophthalmol 1944; 22: 394-400.

6 Albert DM, Rubenstein RA, Scheie HG. Tumor metastasis to the eye, Part I. Incidence in 213 patients with generalized malignancy. Am ff Ophthalmol 1967; 63: 723-6.

7 Bloch RS, Gartner S. The incidence of ocular metastatic carcinoma. Arch Ophthalmol 1971; 85: 673-5.

8 Shields JA, Shields CL, Kiratli H, DePotter P. Metastatic tumors to the iris in 40 patients. Am $\mathcal{F}$ Ophthalmol 1995; 119: 422-3.

9 Reddy S, Sexena VA, Hendrickson F, Deutch W. Malignant metastatic disease of the eye: Management of an uncomon complication. Cancer 1981; 47: 810-2.

10 Dobrowsky W. Treatment of choroidal metastases. $\mathrm{Br} f$ Radiol 1988; 61: 140-2.

11 Ferry AP, Font RL. Carcinoma metastatic to the eye and orbit I. A clinicopathologic study of 227 cases. Arch Ophthalmol 1974; 92: 276-86.

12 Shields JA, Shields CL. Intraocular tumors: a text and atlas. 4th ed. Philadelphia: WB Saunders, 1992: 208.

13 American Cancer Society. American cancer society: cancer facts and figures. New York: American Cancer Society, 1993: 7.

14 Freedman ML, Folk JC. Metastatic tumors to the eye and orbit: patient survival and clinical characteristics. Arch Ophthalmol 1987; 105: 1215-9. 